\title{
Access to palliative care varies widely across Canada
}

A ccess to high-quality palliative care in Canada should not depend on your area code, according to the Canadian Hospice Palliative Care Association, a nonprofit organization that advocates for improved palliative care services for Canadians. And yet geography does dictate quality of care, the association states in a June 2010 report, Quality End-of-Life Care? It Depends on Where you Live ... and Where You Die (www.chpca.net/resource_doc_library /HPC_Policy_Brief_Systems_Approach June_2010.pdf).

"Individuals with life-threatening illnesses who are lucky enough to live in areas served by best practice programs benefit and receive a higher standard of care than those in regions without an integrated approach to endof-life care," the report states. "Access to high quality care should not depend on luck."

Though some jurisdictions have health centres that do palliative care fairly well, no single province or territory stands outs as the gold standard for others to emulate, says Sharon Baxter, executive director of the Canadian Hospice Palliative Care Association. Manitoba was an early leader in palliative care, says Baxter, but has since fallen into the middle of the pack. New Brunswick has a good home-based palliative care program, she says, but offers little palliative care training to staff in long-term care facilities.

"It's hard to say who is best," says Baxter. "Everybody does some things well, but nobody is doing really well in all areas."

Best-practice programs have several traits in common, the association's report states, including components such as assessment tools, collaborative care plans, interdisciplinary teams and support for family caregivers. There are certain pockets of excellence across Canada, the report notes, where palliative care providers offer such services.

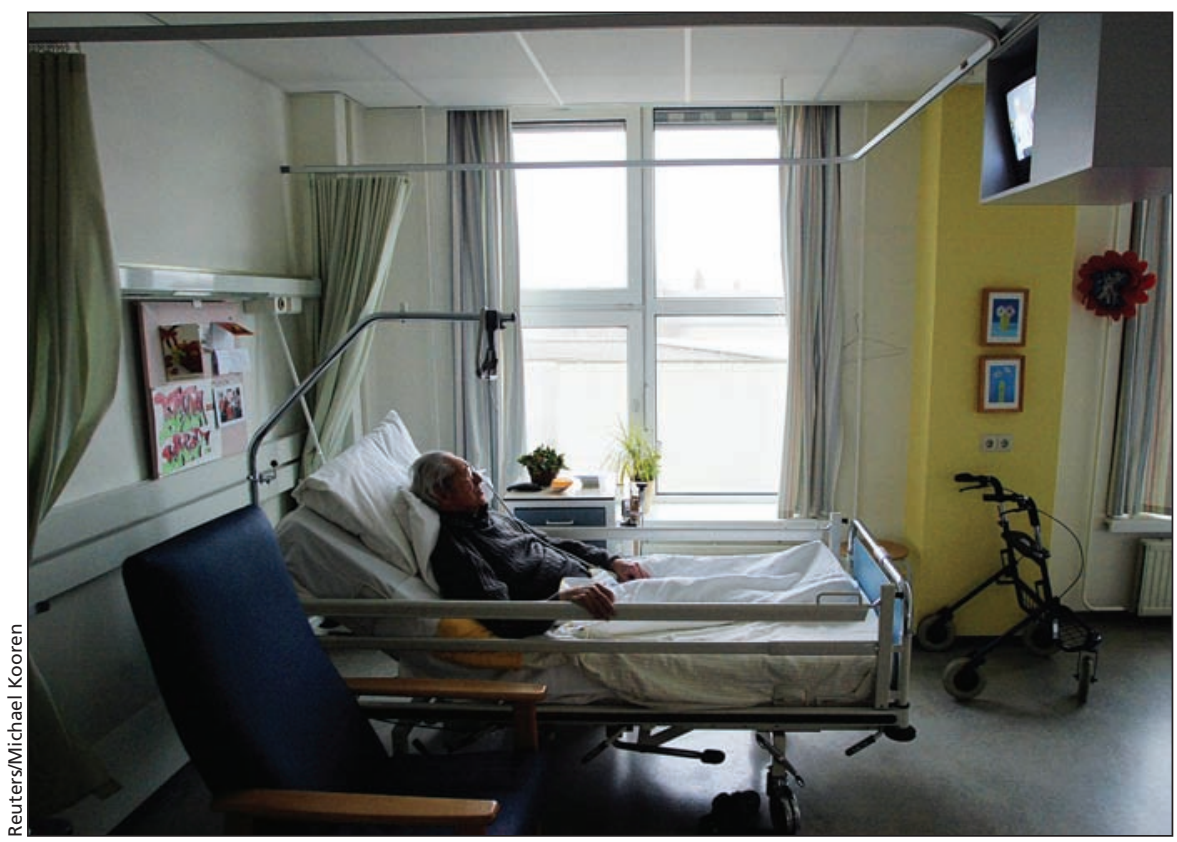

A patient asleep in a palliative care facility.

These providers include Victoria Hospice in British Columbia, which has a 24-hour on-call home visit service and a research department, and provides short-term crisis consultation; the Edmonton Regional Palliative Care Program in Alberta, which has been instrumental in training palliative care specialists and developing quality assessment tools; and the New Brunswick Extra-Mural Program, which aims to provide consistent and seamless palliative care between the hospital and the home.

"Right now, access to high quality care at the end of life mainly depends on where people live in Canada," the document states. "Their ability to move easily from home to hospital (if they need that level of care) back to home or to a hospice also depends on where they live."

People who live in remote areas have a particularly difficult time accessing high-quality palliative care. Though there are several good rural palliative programs, urban centres tend to offer the best and most diverse palliative services. This is a major challenge in a geographically expansive country such as Canada, but rural residents deserve good palliative care, too, says Baxter. "You should not be dragged 100 miles away from your home to die."

In May 2008, a detailed report on the variation between provinces of homebased palliative care services was released by the Quality End-of-Life Care Coalition of Canada, a network of 30 national organizations that promote highquality palliative care for Canadians (www.chpca.net/qelccc/hphc-progress _report/Hospice_Palliative_Home_Care _Progress_Report-final.pdf). The report claims that although the majority of Canadians want to die at home, about $60 \%$ now die in hospitals.

"The gap between what Canadians want at the end of life and what they experience has been due, in part, to the variability in the hospice palliative care services provided at home in different jurisdictions," the report states.

There were some services, however, that were offered in most of the provinces and territories that participated in the survey (Quebec did not participate). All participants, for instance, 
had eligibility criteria and a standard process to access palliative care in the home, and all accommodated patient's access to pharmacists (Table 1).

All jurisdictions except one (Prince Edward Island) covered the cost of some medical supplies and equipment; all but two (Nova Scotia and PEI) provided expansive coverage for drugs used in home-based palliative care; and only three (Ontario, Nova Scotia, Northwest Territories) lacked policies to promote team-based palliative care. The majority of jurisdictions also provided interprofessional education and training, and had policies regarding the distribution, storage, handling and disposal of drugs.

The areas of home-based palliative care that were not consistently offered across provincial borders included policies to ensure 24/7 access to case management services (found in four jurisdictions: Saskatchewan, Ontario, New Brunswick, Newfoundland and Labrador); policies to ensure $24 / 7$ access to nursing and personal care (found in six jurisdictions: British Columbia, Alberta,
Manitoba, Ontario, New Brunswick, Nova Scotia); and wait-time tracking (found in four jurisdictions: Ontario, New Brunswick, Nunavut, Yukon).

"While all jurisdictions have made progress and more Canadians are now able to receive hospice palliative home care, there is still much more to be done," the report concludes. "Although many of the right policies and procedures are in place, the number of people who actually receive high quality hospice palliative home care services is still limited by lack of training - particularly for personal support workers, lack of resources, geography (i.e., people living in urban centres are more likely to receive comprehensive hospice palliative home care than those in rural or remote communities), and restrictive eligibility criteria."

According to Baxter, every province could do more to help Canadians access the services they need at the end of their lives. "We will never have a palliative care physician in every community," she says. "But we all have to do a better job in serving Canadians in the future." - Roger Collier, CMAJ

CMAJ 2011. DOI:10.1503/cmaj.109-3763

Sixth of a series on end-of-life care

Part I: Preparing for the inevitable (www.cmaj.ca/cgi/doi/10.1503/cmaj .109-3704)

Part II: Advance directives: obstacles in preparing for the worst (www.cmaj.ca/cgi/doi/10.1503/cmaj .109-3743)

Part III: End-of-life planning framework calls for fewer checklists, more conversation

(www.cmaj.ca/cgi/doi/10.1503/cmaj .109-3746)

Part IV: Tools help patients tackle tough choices for end-of-life care (www.cmaj.ca/cgi/doi/10.1503/cmaj .109-3750)

Part V: National home care standards urged

(www.cmaj.ca/cgi/doi/10.1503/cmaj .109-3731)

Table 1: Home-based palliative care across Canada

\begin{tabular}{|c|c|c|c|c|c|c|c|}
\hline Province/territory & $\begin{array}{l}\text { Wait time } \\
\text { tracking }\end{array}$ & $\begin{array}{c}24 / 7 \text { case } \\
\text { manage- } \\
\text { ment }\end{array}$ & 24/7 nursing & $\begin{array}{l}\text { Protocol for } \\
\text { timely } \\
\text { referrals }\end{array}$ & $\begin{array}{c}\text { Policy for } \\
\text { team-based } \\
\text { care }\end{array}$ & $\begin{array}{l}\text { Support for } \\
\text { research }\end{array}$ & $\begin{array}{l}\text { Interprofes- } \\
\text { sional } \\
\text { education }\end{array}$ \\
\hline British Columbia & & & $x$ & & $x$ & $x$ & \\
\hline Alberta & & & $x$ & & $x$ & $x$ & $x$ \\
\hline Saskatchewan & & $x$ & & $x$ & $x$ & $x$ & \\
\hline Manitoba & & & $\mathrm{x}$ & $x$ & $\mathrm{x}$ & $x$ & $x$ \\
\hline Ontario & $x$ & $x$ & $x$ & $x$ & & $x$ & $x$ \\
\hline New Brunswick & $x$ & $x$ & $x$ & $\mathrm{x}$ & $x$ & $x$ & \\
\hline Nova Scotia & & & $x$ & & & & \\
\hline Prince Edward Island & & & & $x$ & $x$ & & $x$ \\
\hline Newfoundland and Labrador & & $x$ & & & $x$ & & $x$ \\
\hline Nunavut & $x$ & & & $x$ & $x$ & & $x$ \\
\hline Northwest Territories & & & & $\mathrm{x}$ & & & \\
\hline Yukon & $x$ & & & & $x$ & & $x$ \\
\hline
\end{tabular}

